\title{
Numerical Simulation and Experimental Validation of the Vibration Modes for a Processing Reciprocating Compressor
}

\author{
Ying Zhao, Jiahao Chen, Qiang Zhou, Xiaohan Jia, and Xueyuan Peng \\ Xian Jiaotong University, No. 28, Xianning West Road, Xi'an, Shaanxi 710049, China \\ Correspondence should be addressed to Xueyuan Peng; xypeng@mail.xjtu.edu.cn
}

Received 14 March 2017; Revised 29 June 2017; Accepted 6 July 2017; Published 22 August 2017

Academic Editor: Marc Thomas

Copyright (c) 2017 Ying Zhao et al. This is an open access article distributed under the Creative Commons Attribution License, which permits unrestricted use, distribution, and reproduction in any medium, provided the original work is properly cited.

\begin{abstract}
The low-order vibration modes of a reciprocating compressor were studied by means of numerical simulation and experimental validation. A shell element model, a beam element model, and two solid element models were established to investigate the effects of bolted joints and element types on low-order vibration modes of the compressor. Three typical cases were compared to check the effect of locations of moving parts on the vibration modes of the compressor. A forced modal test with the MRIT (Multiple References Impact Test) technique was conducted to validate the simulation results. Among four numerical models, the solid element model with the bolt-pretension method showed the best accuracy compared with experimental data but the worst computational efficiency. The shell element model is recommended to predict the low-order vibration modes of the compressor with regard to effectiveness and usefulness. The sparsely distributed bolted joints with a small bonded region on the contact surface were key bolted joints that had greater impacts on the low-order vibration modes of the compressor than the densely distributed bolted joints. The positions of the moving parts had little effect on the low-order vibration modes of the compressor.
\end{abstract}

\section{Introduction}

Reciprocating compressors are widely used in mechanical and petrochemical industries. Dynamic forces on reciprocating compressors such as unbalanced inertial forces, gas forces inside the cylinder, cross-head forces, and acoustic shaking forces can induce severe vibrations on compressor, pipes, vessels, small-bore appendages, and the skid [1]. Excessive vibration may lead to fatigue failure, capacity loss, and increasing maintenance costs. To ensure the safe and reliable operation of the compressor system, the vibration modes of the compressor, mainly including MNFs (mechanical natural frequencies) and mode shapes, should be studied during the design stage. FEA (finite element analysis) and experimental modal test were applied to identify the vibration modes of structures.

The first step of the numerical simulation is to build the FEA model of the structure. A key point of numerical modelling is to choose the proper element type for the structure. Many studies have been conducted on the selection of element types for reciprocating compressors in order to simulate the dynamic characteristics of the compressor accurately and efficiently. The solid element model can simulate the actual geometric shape and physical morphology of the compressor, but its disadvantages include large memory cost and time-consuming operation. Benjamin [2] compared the vibration velocity responses and dynamic stress distributions of the cylinder nozzle and pulsation filter bottle using the shell element model and the beam element model and found that the more detailed shell model showed better agreement with the field measurement than the simpler beam element model. Harper et al. [3] noted that beam elements were suitable for static loads such as lifting loads, but dynamic analyses often required shell or solid elements for certain parts of the model to accurately simulate local flexibility. Passeri et al. [4] generated a superelement of the compressor frame by the solid element model based on the substructuring technique to achieve a balance between calculation accuracy and computation time. However, little attention has been focused on the influence of element types on MNFs and mode shapes of reciprocating compressors. 


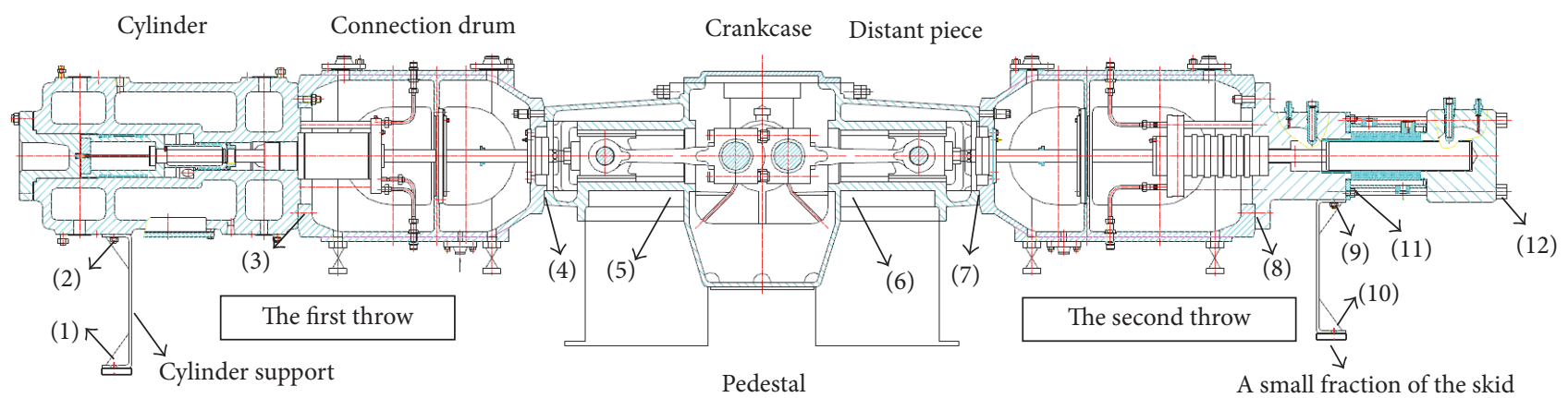

FIGURE 1: The balanced-opposed reciprocating compressor.

Proper modelling of bolted joints is critical to estimating the dynamic characteristics of reciprocating compressors. The characteristics of bolted joints have drawn much attention in recent years [5-12]. Pratt and Pardoen [5] proposed nonlinear finite element models to predict the load-elongation behaviour of conical-head bolted lap joints and verified simulation results by the comparison to test data. Ahmadian and Jalali [6] established a detailed parameter model of a bolted joint interface and extracted modal parameters by the force-state mapping method. Kim et al. [7] established four kinds of numerical models to investigate the pretension effect and contact behaviour of bolted joints. Compared with experimental results, the solid bolt model, which was modelled using three-dimensional solid elements and surface-to-surface contact elements, provided the best accuracy; the coupled bolt model, which coupled the degrees of freedom between the head/nut and the flange, showed the best effectiveness with respect to computational time. Nevertheless, the numerical modelling methods of complex assemblies with many bolted joints such as reciprocating compressors were discussed by a small number of researchers.

During the operation, the compressor crankshaft was driven by the motor. The rotation of the crankshaft will be converted to the reciprocating motion of the piston through the crank-connecting rod mechanism, which consists of the crankshaft, connecting rod, cross-head, piston rod, and piston. The locations of the reciprocating moving parts vary between the TDC (top dead centre) and BDC (bottom dead centre) periodically as the crankshaft is rotated. The distance between TDC and BDC is defined as the stroke of the compressor. No research has been conducted on the influence of the locations of moving parts on the vibration modes of reciprocating compressors.

Modal analysis is widely used in many fields such as architecture, bridges, and vehicles to extract the vibration modes of structures [13-20]. Experimental modal testing is an important type of modal analysis and has rapidly developed in recent years. Aras et al. [15] conducted an ambient vibration survey to identify the dynamic characteristics of a historical masonry palace and modified the finite element model by adjusting the elasticity modulus based on the experimental results. Ribeiro et al. [16] identified MNFs, mode shapes, and damping coefficients of a bowstring-arch railway bridge by an ambient vibration test. Minette et al. [18] conducted a SIMO (single-input and multiple-output) modal test for an electrical submersible pump and extracted its MNFs by the least square complex exponential method. However, there is little research on the experimental identification of vibration modes of reciprocating compressors.

In this paper, the low-order vibration modes of a processing reciprocating compressor were studied through finite element analysis and modal testing. Two solid element models using the bolt-pretension method and the surfacebonded method, a shell element model, and a beam element model were established to investigate the influence of element types and bolted joints on the low-order vibration modes of the compressor. The key bolted joints of the compressor were identified based on the analyses of contact statuses on the interfaces between bolted flanges. Three typical cases were compared to study the effect of the locations of moving parts on the low-order vibration modes of the compressor. A forced modal test with the MRIT (Multiple References Impact Test) technique was conducted to validate the numerical results.

\section{Numerical Simulation}

2.1. Geometric Model. The processing reciprocating compressor investigated in this paper is a balanced-opposed hydrogen compressor with a rated speed of $980 \mathrm{r} \cdot \mathrm{min}^{-1}$, rated shaft power of $73 \mathrm{~kW}$, and total mass of $12500 \mathrm{~kg}$. The compressor has two throws and four stages, as shown in Figure 1. Hereinafter, the first throw refers to the first and second stages, while the second throw corresponds to the third and fourth stages. The compressor body mainly consists of the crankcase, distant pieces, connection drums, cylinders, cylinder supports, and pedestal. These parts are connected through bolted joints. To study the influence of bolted joints on the vibration modes of the compressor, twelve groups of bolted joints (a total of 74 bolted joints) were included in subsequent numerical analyses, as shown in Figure 1. Other bolted joints, small features such as fillets and small holes, and some unimportant parts such as gas valves and lubricating pipes were removed to improve the calculation efficiency. Since the high-order harmonics of the periodic excitation forces such as the gas forces, cross-head guide forces, and acoustic shaking forces are very tiny and 


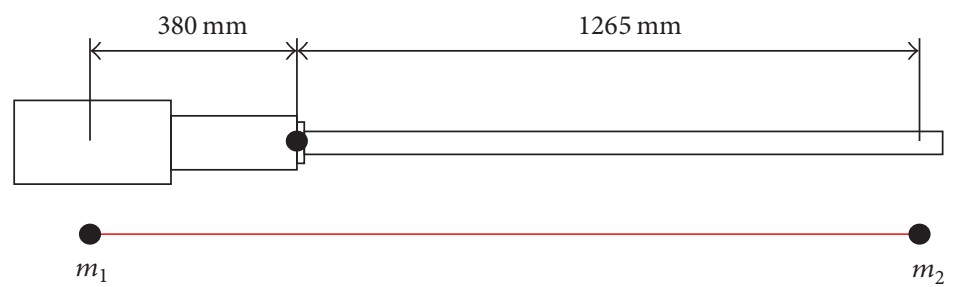

(a) The first throw of piston and piston rod
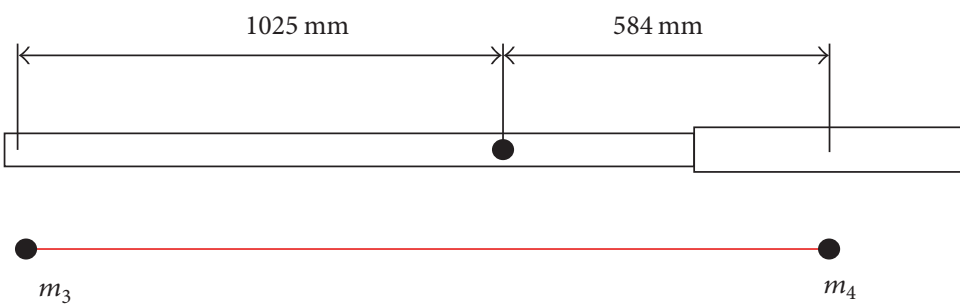

(b) The second throw of piston and piston rod

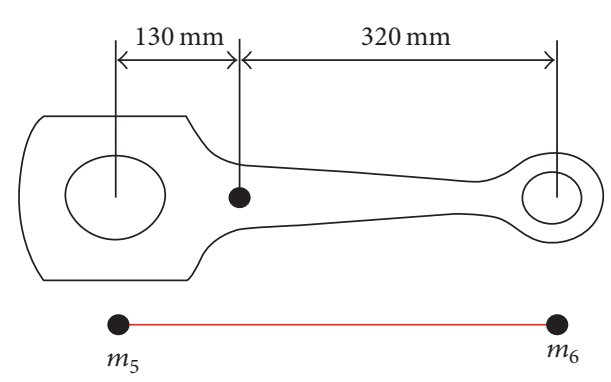

(c) The connection rod

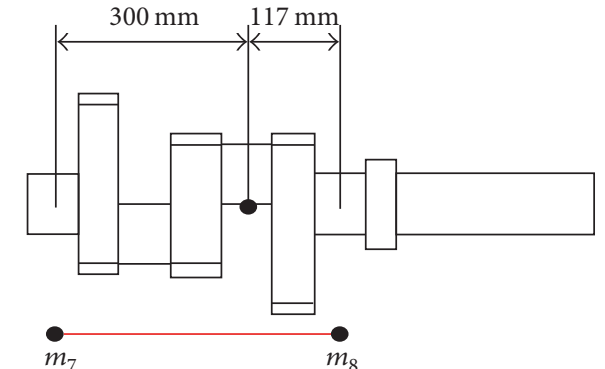

(d) The crankshaft

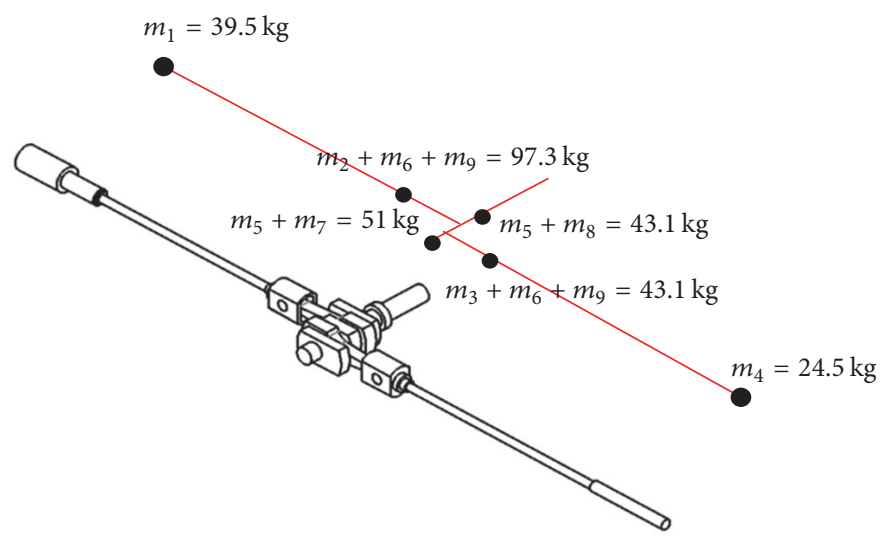

(e) The crank-connecting rod mechanism

FIGURE 2: The equivalence masses of moving parts.

high-order resonances have little effect on the reciprocating compressor, only the low-order vibration modes of the reciprocating compressor were discussed in this paper. The frequency range for the modal analysis of the reciprocating compressor was set as $0-100 \mathrm{~Hz}$ according to the literature [21].

The moving parts inside the compressor body were simplified as point masses by the equivalent principle of mass, as shown in Figure 2. A total of 6 point masses were applied on the FEA model. Four of them were equivalent reciprocating masses and applied on cylinder walls and crosshead guide walls, while the others were equivalent rotating masses and applied on bearing seats of the crankcase. To study the influence of locations of moving parts on the vibration modes of the compressor, three typical cases were compared in which the equivalent reciprocating masses were applied on the location of TDC, BDC, and their midpoint.

2.2. Numerical Models. To assess the effect of element types and bolt joints on the accuracy and efficiency of the numerical simulation of vibration modes for the reciprocating compressor, two solid element models using the bolt-pretension method and the surface-bonded method, a shell element model, and a beam element model were established. 


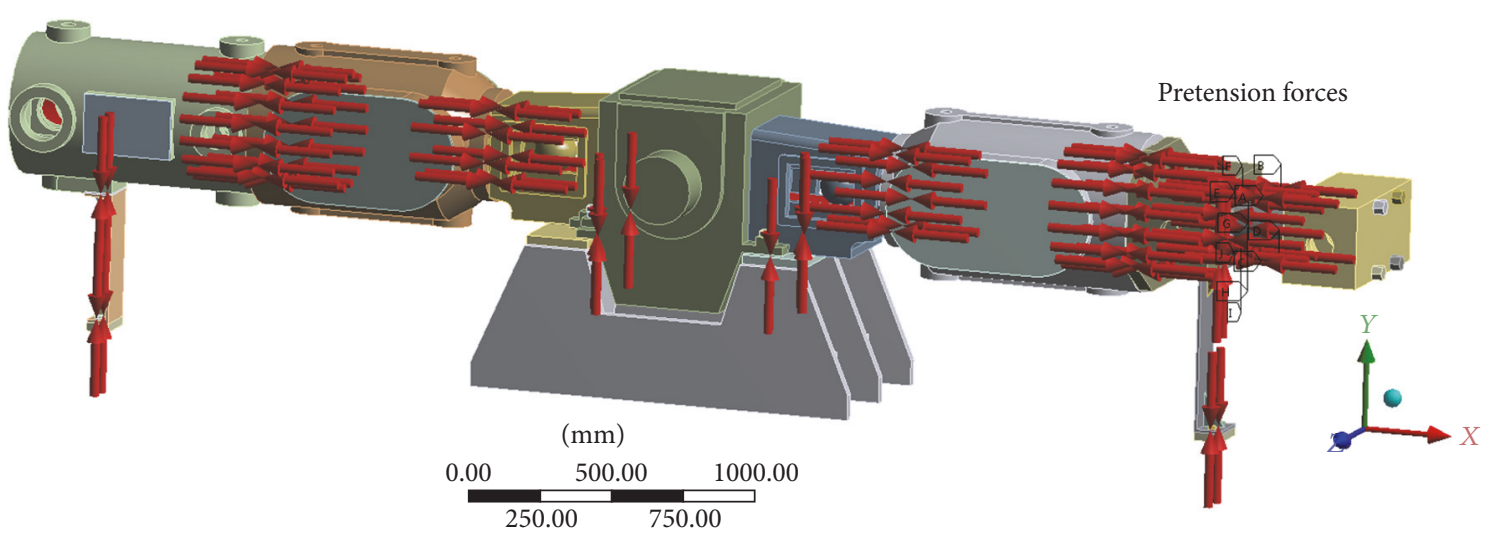

Figure 3: The solid element method with the bolt-pretension method.

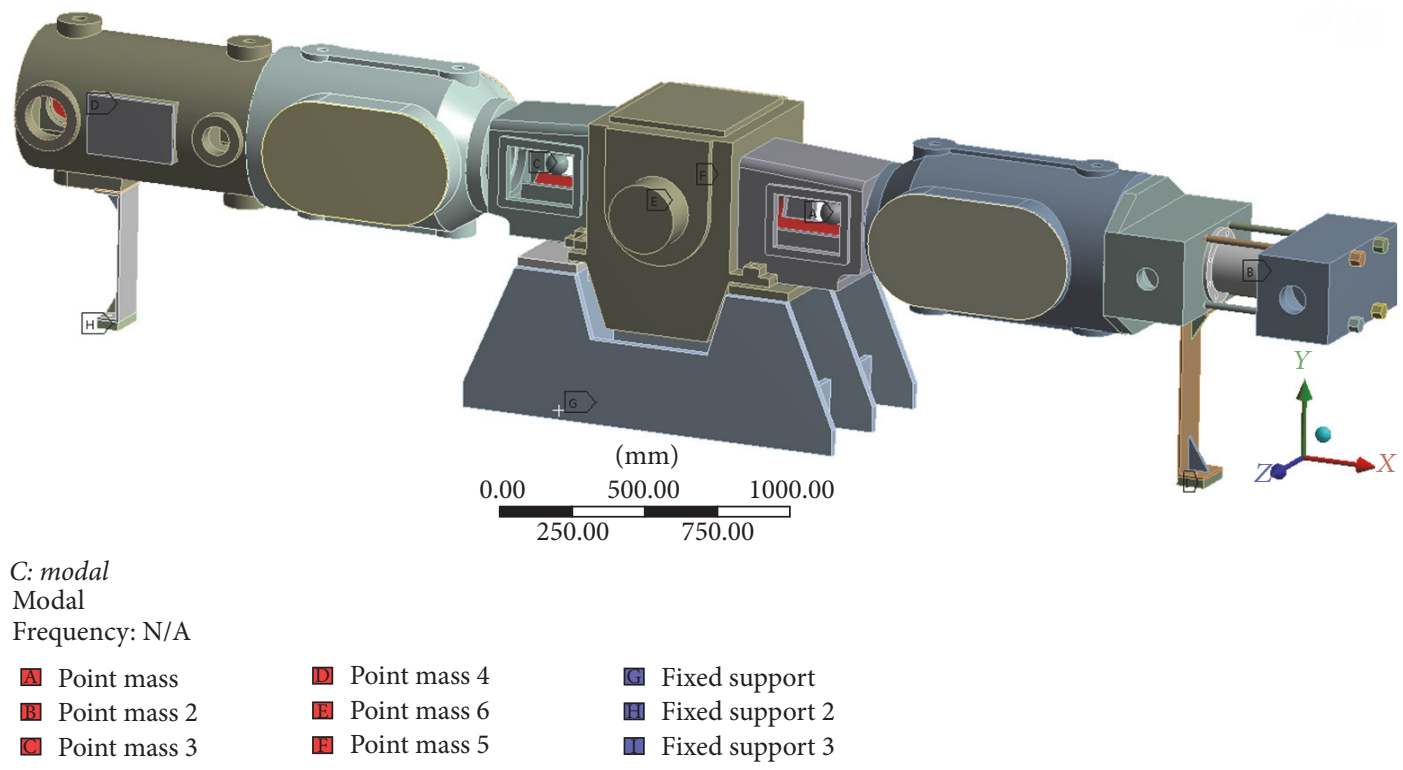

FIgURE 4: The solid element method with the surface-bonded method.

2.2.1. Two Kinds of Solid Element Models. The solid element models were modelled using 3D (three-dimensional) solid elements, known as SOLID187 in ANSYS. This type of element is defined by 20 nodes, and each node has three translational DOFs (degrees of freedom). Two methods, namely, the bolt-pretension method and the surface-bonded method, were adopted to investigate the influence of bolted joints to the low-order vibration modes of the compressor.

(1) The Bolt-Pretension Method. The solid element model with the bolt-pretension method, as shown in Figure 3, was the most realistic model among the four FEA models introduced in this paper. In this method, both the pretension force and contact behaviour of bolted joints were considered. The pretension force was generated in the mid-plane of the bolt shaft using the bolt-pretension element, known as PRETS179 in ANSYS. The pretension force was calculated by the formula recommended in the mechanical design handbook [22]:

$$
F_{a}=(0.6-0.7) A_{s} \sigma_{s}
$$

where $F_{a}$ is the pretension force, $A_{s}$ is the nominal crosssectional area of the bolt, and $\sigma_{s}$ is the yield strength of the material. In addition, the surface-to-surface contact pairs, which consisted of target elements and contact elements, were applied on the interfaces between the bolted flanges and set to frictional types with a friction coefficient of 0.2 .

(2) The Surface-Bonded Method. The surface-bonded method was much simpler than the bolt-pretension method due to the ignorance of bolted joints. In this method, all bolted joints were removed except the connecting long bolts of the thirdand fourth-stage cylinders, as shown in Figure 4. All of the surface-to-surface contact pairs on the interfaces between bolted flanges were set to the bonded type, which means the whole region of the contact area was assumed to be tightly attached.

2.2.2. The Shell Element Model. Some researchers [9] noted that not all regions of the interfaces between bolted flanges were well attached under the pretension force. The region 


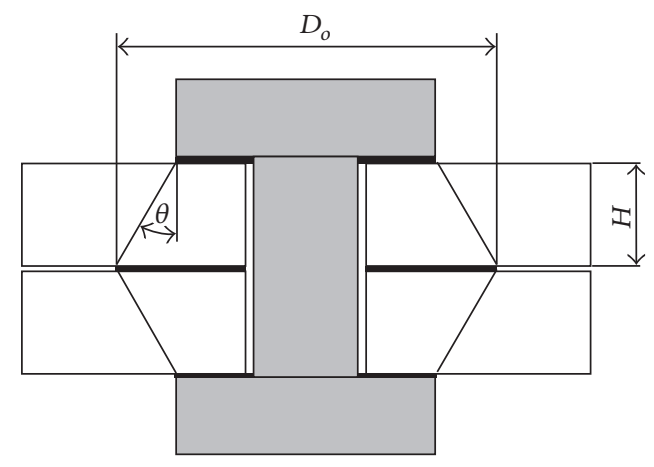

FIGURE 5: Stress distribution region between bolted flanges.

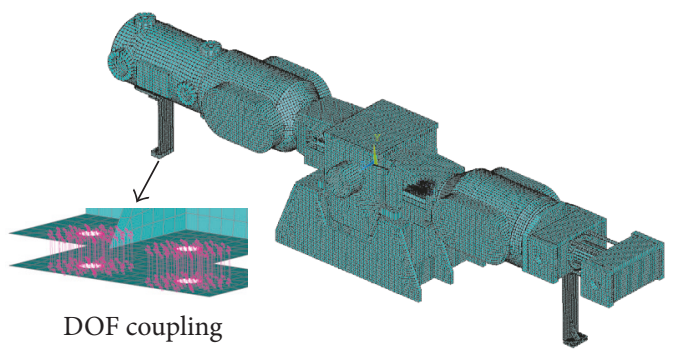

Figure 6: The shell element model.

near the screw hole was tightly attached while the region far away from the screw hole was not closely contacted. The theoretical stress distribution region between bolted flanges was approximated to a truncated cone [9], as shown in Figure 5.

In the shell element model, the compressor body was meshed with 3D shell elements, known as SHELL181 in ANSYS. This type of element is defined by 4 nodes, and each node has three translational DOFs and three rotational DOFs. There was no bolted joint included in this model except the connecting long bolts of the third- and fourth-stage cylinders. The pretension effect of the bolted joints was considered by the DOF coupling of nodes in the theoretical bonded region which was an annular region around the screw hole, as shown in Figure 6. The outer diameter of the theoretical bonded region $D_{o}$ was calculated by

$$
D_{o}=D_{w}+2 H \tan \theta \text {, }
$$

where $D_{w}$ is the outer diameter of the washer, $H$ is the thickness of the flange, and $\theta$ is the half-apex angle of the truncated cone which was suggested to be less than $45^{\circ}$ in the literature [11] and taken as $40^{\circ}$ in this model.

2.2.3. The Beam Element Model. The beam element model as shown in Figure 7 was the simplest model among these four numerical models. The cylinders, cylinder supports, connection drums, distant pieces, and crankcase were simplified as $3 \mathrm{D}$ beam elements, known as BEAM188 in ANSYS. This type of element is defined by 2 nodes, and each node has three translational DOFs and three rotational DOFs. However, the pedestal was meshed by 3D shell elements (SHELL181).

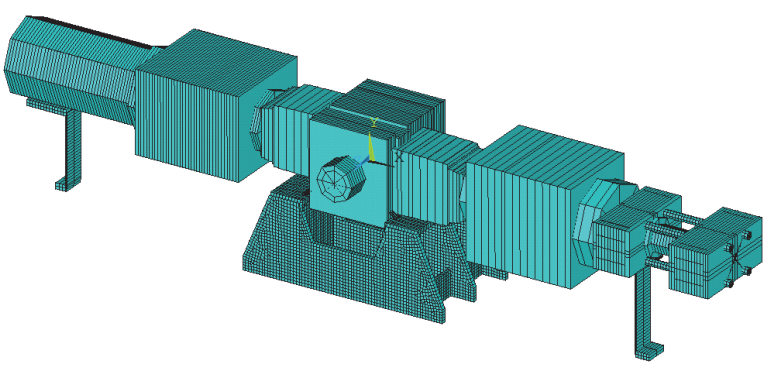

Figure 7: The beam element model.

Moreover, there was no bolt except the connecting long bolts of the third- and fourth-stage cylinders included in this model, and all of the connections between different parts were considered as rigid connections.

After building the FEA models, the bottom surfaces of the pedestal and the small fractions of the skid under the cylinder supports were fixed as constrained elements. For the solid element model with the bolt-pretension method, a nonlinear static analysis was first performed to evaluate the contact status of the interfaces between bolted flanges, and a pretension modal analysis was subsequently conducted to obtain the low-order MNFs and mode shapes of the compressor. For the other three FEA models, the modal analysis was conducted directly to extract the low-order vibration modes of the compressor.

\section{Experimental Validation}

3.1. Forced Modal Test. A forced modal test with the MRIT (Multiple References Impact Test) technique was performed to identify the vibration modes of the compressor and validate the numerical results. The selection of the reference points is an important step in the modal test. The reference points should avoid the modal nodes of vibration modes of interest, and the modal shapes should be significant at the reference points to ensure that the FRF curves have significant peaks. As for this reciprocating compressor with two throws of cylinders, the excitations on one end of the compressor are difficult to arouse obvious vibrations on the other end, so we selected two reference points on each throw of cylinder based on pretests and numerical results. The four reference points, that is, the excitation points, are shown in Figure 8. The response points should be able to identify all the mode shapes of interest and avoid the modal confusion. Based on the mode shapes obtained by the FEA analyses, the response points were mainly arranged at geometrical vertexes and appropriately increased at positions of weak stiffness. A total of 136 response points were selected, as shown in Figure 8.

The experimental system is shown in Figure 9. The excitations were applied by a PCB 086D50 type impact hammer with the sensitivity of $0.23 \mathrm{mV} \cdot \mathrm{N}^{-1}$, measuring range of $22240 \mathrm{~N}$, and hammer weight of $2.5 \mathrm{~kg}$. The responses were acquired by a PCB 356B18 type three-axis acceleration sensor with a measuring range of $\pm 5 \mathrm{~g}$ and frequency span of $0.5-3000 \mathrm{~Hz}$. The sensitivities of the acceleration sensor in the 


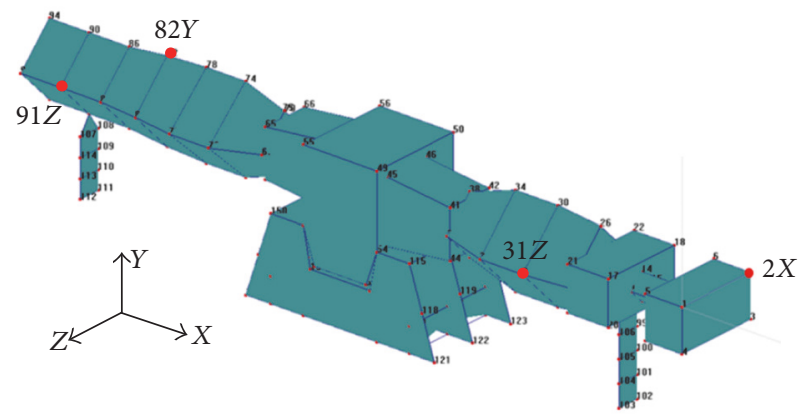

FIGURE 8: Excitation and response points.

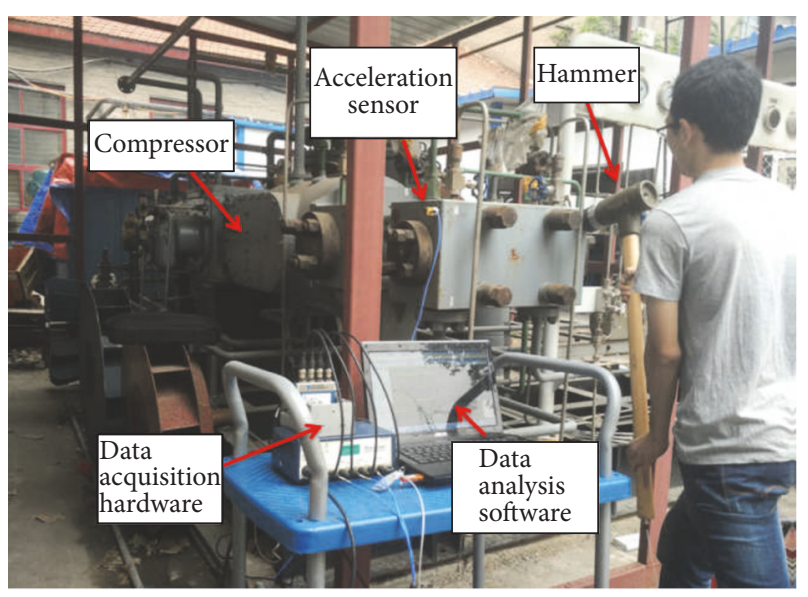

FIGURE 9: The forced modal test process.

$X, Y$, and $Z$ directions were $1030 \mathrm{mV} \cdot \mathrm{N}^{-1}, 1048 \mathrm{mV} \cdot \mathrm{N}^{-1}$, and $992 \mathrm{mV} \cdot \mathrm{N}^{-1}$, respectively. An NI 9234 data acquisition system with four channels was used to simultaneously record the force signal and accelerator signals in three directions. Signals obtained from the modal test were recorded and processed by the data analysis software Coinv DASP V10 developed by China Orient Institute of Noise and Vibration. During the modal test process, each point was gathered three times, and the measured data were linearly processed to reduce the error of the experiment.

3.2. Experimental Results. The modal parameters of the reciprocating compressor in the frequency range of $0-100 \mathrm{~Hz}$ were estimated by the ERA (Eigen Realization Algorithm) method which is one of the advanced time-domain modal identification methods. Figure 10 shows the stabilization diagram, four CMIFs (Complex Modal Indicator Functions) were presented, and seven vibration modes were identified within the frequency range of interest. The mode vectors were normalized by the mass normalization method.

The MAC (modal assurance criterion) is a scalar constant used to denote the similarity between one mode vector and another, and lies in the range from 0 to 1 . The higher the MAC, the better the orthogonality between the mode vectors. The

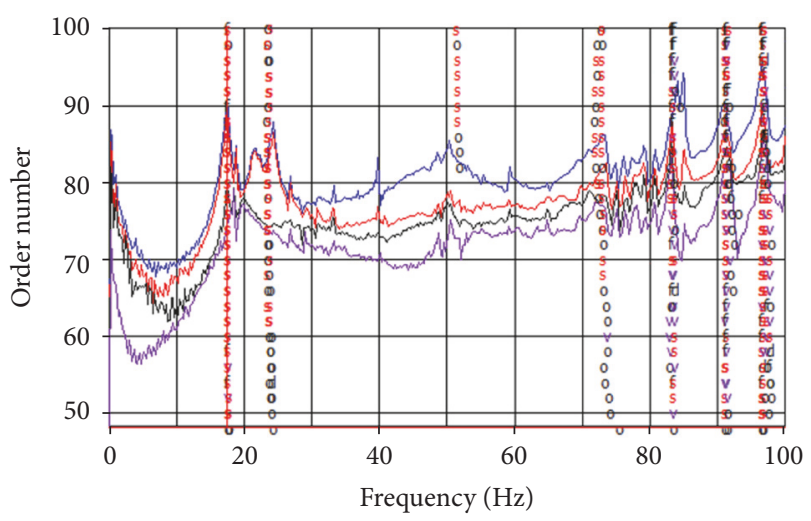

FIGURE 10: Stabilization diagram of the ERA method.

MAC between the $i$ th and $j$ th mode vectors $\left\{\phi_{i}\right\}$ and $\left\{\phi_{j}\right\}$ can be expressed as follows:

$$
\operatorname{MAC}\left(\left\{\phi_{i}\right\},\left\{\phi_{j}\right\}\right)=\frac{\left|\left\{\phi_{i}\right\}^{T}\left\{\phi_{j}\right\}\right|^{2}}{\left(\left\{\phi_{i}\right\}^{T}\left\{\phi_{i}\right\}\right)\left(\left\{\phi_{j}\right\}^{T}\left\{\phi_{j}\right\}\right)}
$$

The MAC matrix of the extracted seven-order vibration modes is shown in Figure 11. It can be seen that the offdiagonal values of the MAC matrix were less than 0.5, which indicated that the seven-order mode vectors had good orthogonality.

Figure 12 shows the extracted seven orders of mode shapes of the compressor. It can been seen that the firstand second-order mode shapes were horizontal bending vibrations (in the $Z$ direction) of the second and first throw of the cylinders, respectively; the third- and fourth-order mode shapes were vertical bending vibrations (in the $Y$ direction) of the second and first throw of cylinders, respectively; the fifth- and seventh-order mode shapes were torsional vibrations around the $X$ direction of the second and first throw of cylinders, respectively; the sixth-order mode shape was overall horizontal vibration along the $X$ direction.

\section{Results and Discussion}

4.1. Effects of Element Types on Vibration Modes of the Compressor. Figure 13 shows the comparison of the low-order MNFs between numerical results of three different element types and experimental results. Figures 14-16 show the loworder mode shapes obtained by three different element types. Table 1 shows the comparison of computational efficiency among different numerical models. It can be seen that the deviation of the low-order MNFs between the solid element model with the bolt-pretension method and experimental data ranged from $-1.4 \%$ to $7.9 \%$; the deviation between the shell element model and experimental data ranged from $-15.3 \%$ to $-6.1 \%$; however, the low-order MNFs obtained from the beam element model were obviously higher than the experimental results with relative errors ranging from $33.0 \%$ to $112.4 \%$. In addition, the low-order mode shapes of the solid element model with the bolt-pretension method and the shell 
TABLE 1: Comparison of computation time and storage space.

Solid element models

\begin{tabular}{lccccc}
\hline & \multicolumn{3}{c}{ Solid element models } & & \\
& Bolt-pretension method & Surface-bonded method & Shell element model & Beam element model \\
& 74 bolted joints & 8 bolted joints & & & 0.03 \\
\hline Computation time/h & 6.8 & 3.7 & 2.3 & 1.74 & 0.01 \\
Storage space/GB & 8.95 & 3.24 & 2.76 & 0.40 \\
\hline
\end{tabular}

\begin{tabular}{|c|c|c|c|c|c|c|c|}
\hline 96.45 & 0.04 & 0.02 & 0.07 & 0.32 & 0.10 & 0.06 & 1.00 \\
\hline 91.29 & 0.04 & 0.11 & 0.03 & 0.40 & 0.12 & 1.00 & 0.06 \\
\hline 83.25 & 0.03 & 0.02 & 0.10 & 0.05 & 1.00 & 0.12 & 0.10 \\
\hline 72.62 & 0.03 & 0.19 & 0.07 & 1.00 & 0.05 & 0.40 & 0.32 \\
\hline 51.26 & 0.02 & 0.04 & 1.00 & 0.07 & 0.10 & 0.03 & 0.07 \\
\hline 23.20 & 0.28 & 1.00 & 0.04 & 0.19 & 0.02 & 0.11 & 0.02 \\
\hline 17.43 & 1.00 & 0.28 & 0.02 & 0.03 & 0.03 & 0.04 & 0.04 \\
\hline & 17.43 & 23.20 & 51.26 & 72.62 & 83.25 & 91.29 & 96.45 \\
\hline
\end{tabular}

FIGURE 11: MAC matrix of the extracted seven mode vectors in the frequency range of $0-100 \mathrm{~Hz}$.

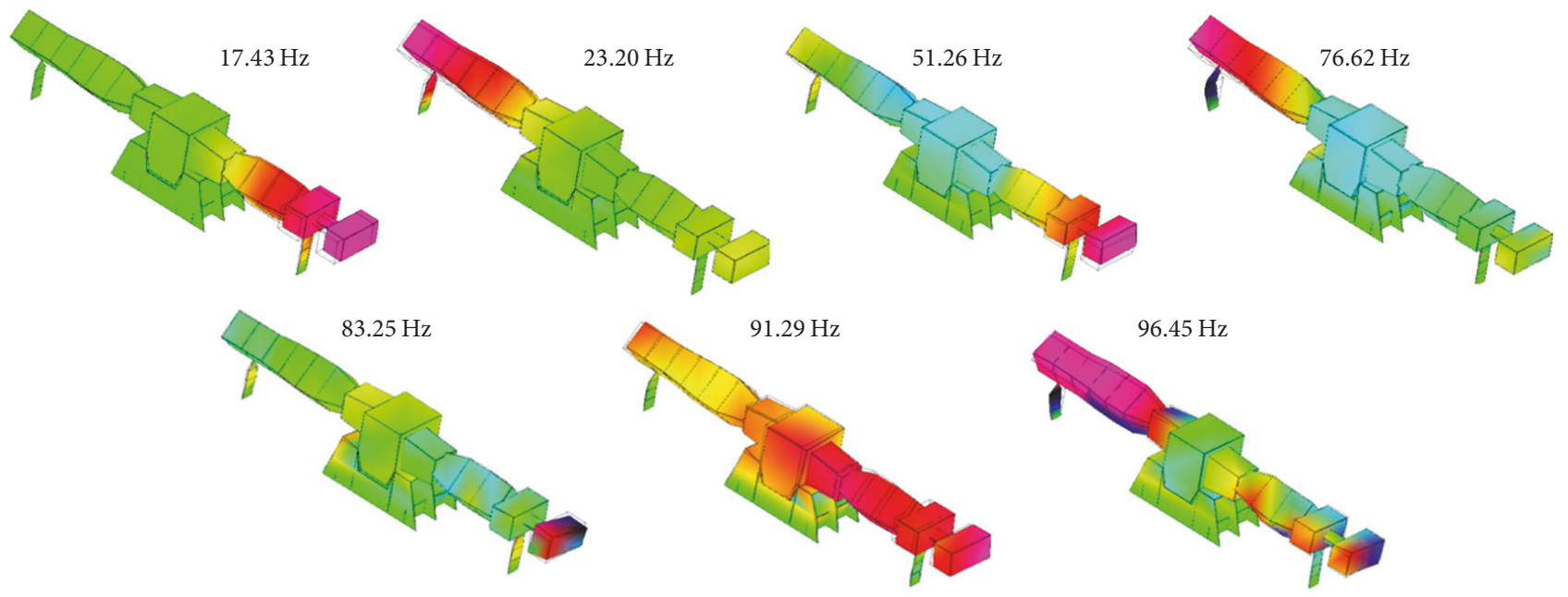

FIGURE 12: Experimental results of mode shapes in the frequency range of 0-100 Hz.

element model fitted well with experimental results, but the fourth- to seventh-order mode shapes of the beam element model were completely different from experimental results.

The significant errors of the beam element model may be caused by two reasons. Firstly, the Beam188 elements in ANSYS are based on Timoshenko beam theory which assumes that the cross section of the element remains plane without distortion after deforming of the structure, so the ignorance of deformation on cross-sections of compressor cylinders will reduce simulation accuracy. Secondly, different components such as cylinders and cylinder supports were connected by rigid beam elements in the beam element model, which may lead to the increase of the overall stiffness and the overestimation of MNFs.

It was concluded that the solid element model with the bolt-pretension method showed the best accuracy compared with experimental results among the three numerical models discussed here. The deviations of the shell element model were within the engineering allowable range, and the shell element model saved $99.6 \%$ of computation time and $80.6 \%$ of storage space compared to the bolt-pretension method. In view of effectiveness and usefulness, the shell element model was recommended to predict the low-order vibration modes of the reciprocating compressor.

\subsection{Effects of Bolted Joints on Vibration Modes of the Compressor}

4.2.1. Comparison between Two Solid Element Models and Experimental Data. Figures 17 and 18 show the comparisons of the low-order MNFs and mode shapes between two 


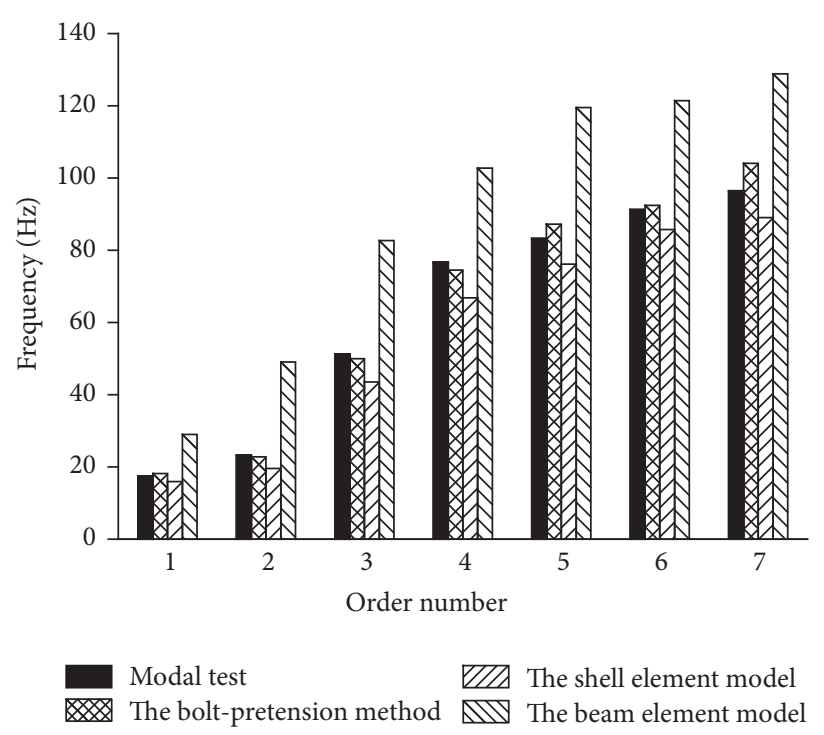

FIGURE 13: Comparison of MNFs between numerical results of different element types and experimental results.
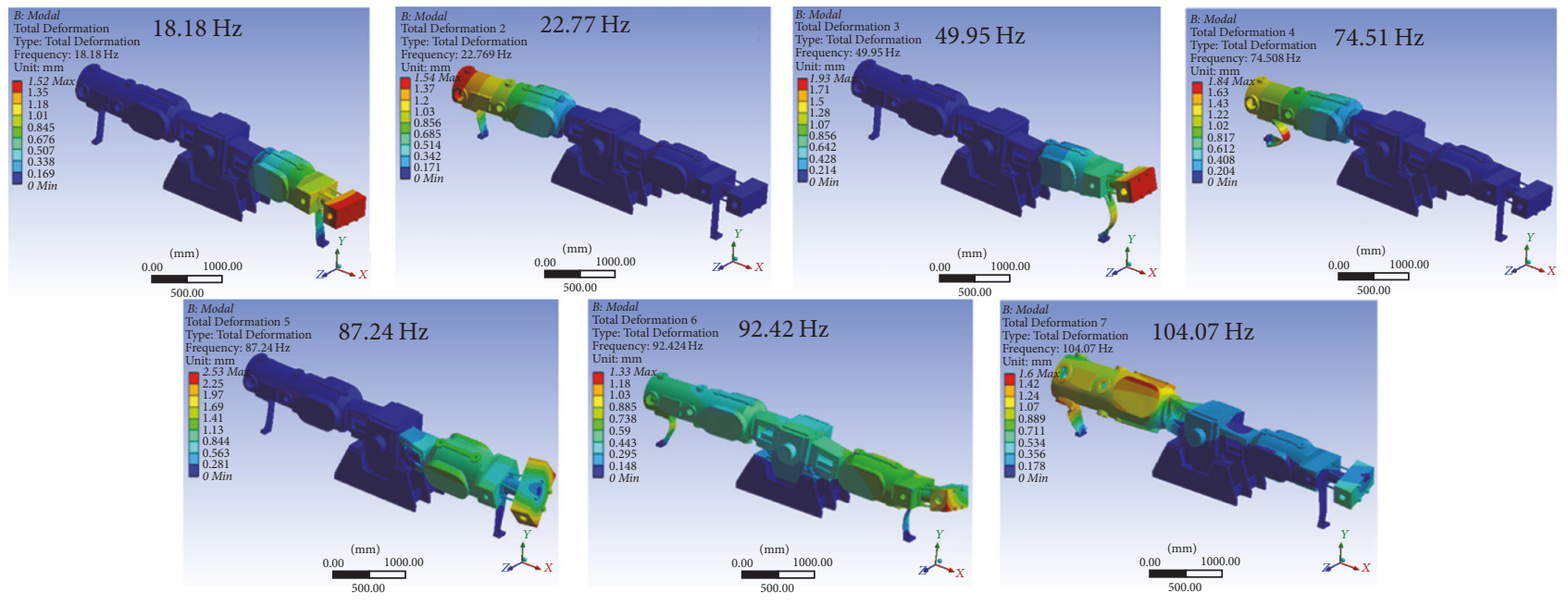

FIGURE 14: Low-order mode shapes of the solid element model with the bolt-pretension method.
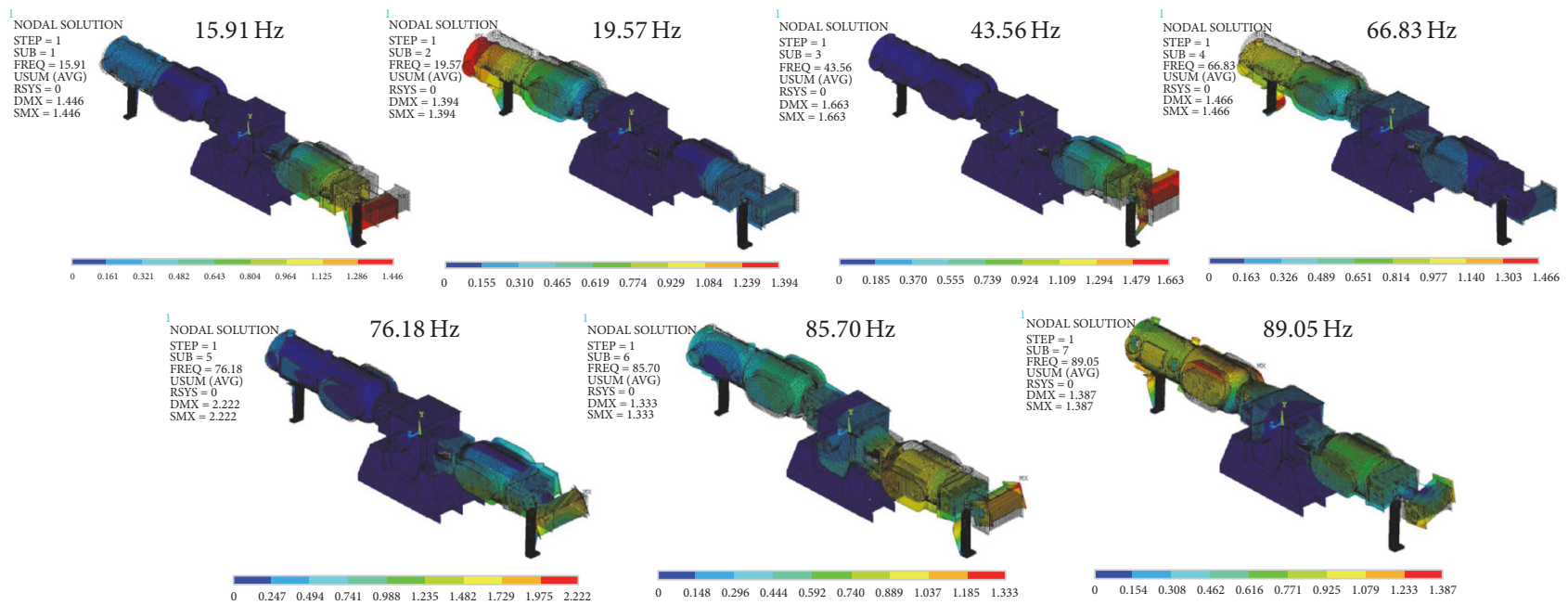

Figure 15: Low-order mode shapes of the shell element model. 

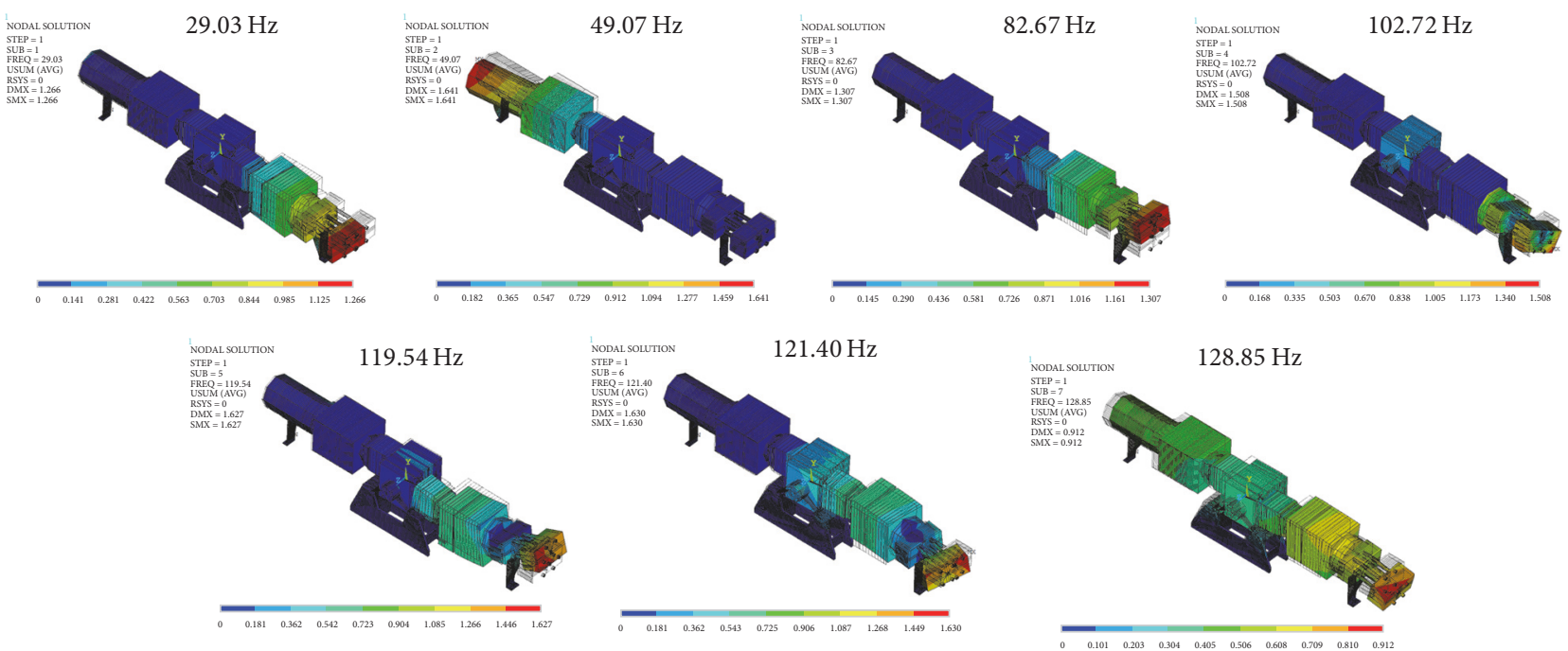

FIGURE 16: Low-order mode shapes of the beam element model.

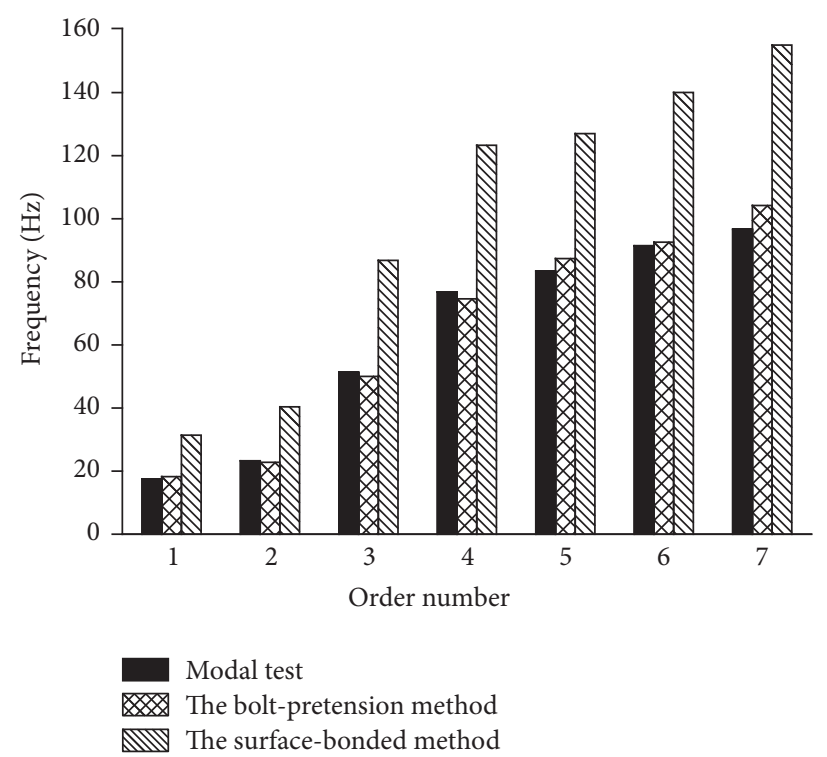

FIGURE 17: Comparison of MNFs between two kinds of solid element models and experimental results.

kinds of solid element models and the experimental data. It can be seen that the deviation of the low-order MNFs between the surface-bonded method and experimental data ranged from $52.3 \%$ to $79.8 \%$ and was obviously higher than that of the bolt-pretension method. The overestimation of MNFs may be caused by the ignorance of pretension effects of bolted joints which will create compression stress between the interfaces and decrease the natural frequencies. Moreover, the first seven mode shapes of the bolt-pretension method were consistent with experimental results, but the fourth- to sixth-order mode shapes of the surface-bonded method were different from experimental results. It was indicated that the bolt-pretension method was effective for identifying low-order vibration modes of complex assemblies with bolted joints such as a reciprocating compressor, while the surface-bonded method could not accurately evaluate the low-order vibration modes of complex assemblies.

4.2.2. Contact Status on the Interfaces between Bolted Flanges. The contact statuses of frictional contact pairs in the solid element model with the bolt-pretension method were extracted from the static analysis results. There are five kinds of contact statuses in ANSYS, and among them the sticking and sliding statuses can be equivalent to the bonded contact [23]. There were two main types of contact status between bolted flanges of the compressor, as shown in Figure 19. The bonded regions on the interfaces between cylinders and cylinder supports and the interfaces between cylinder supports and 


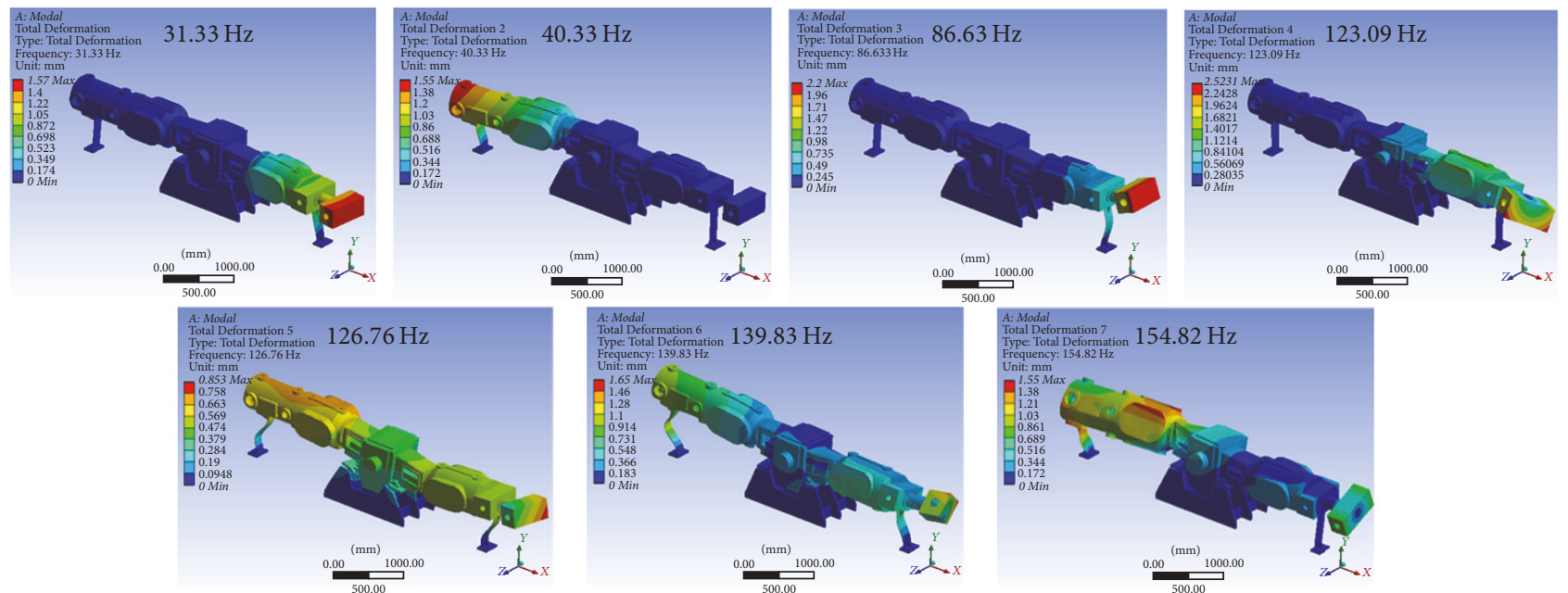

FIGURE 18: Low-order mode shapes of the solid element model with the surface-bonded method.
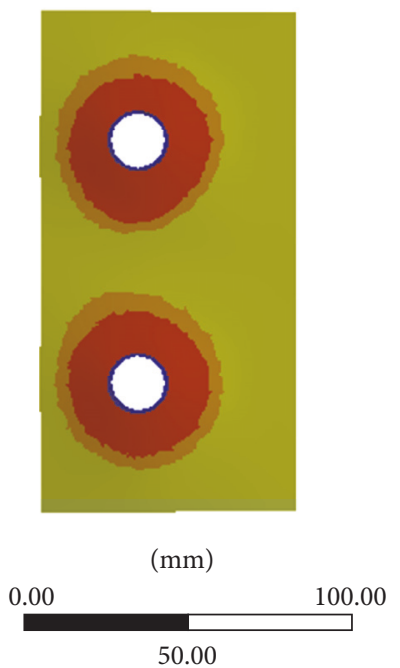

Status

Type: status

Time: 1

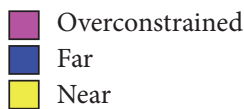

(a) The sparsely distributed bolted joints
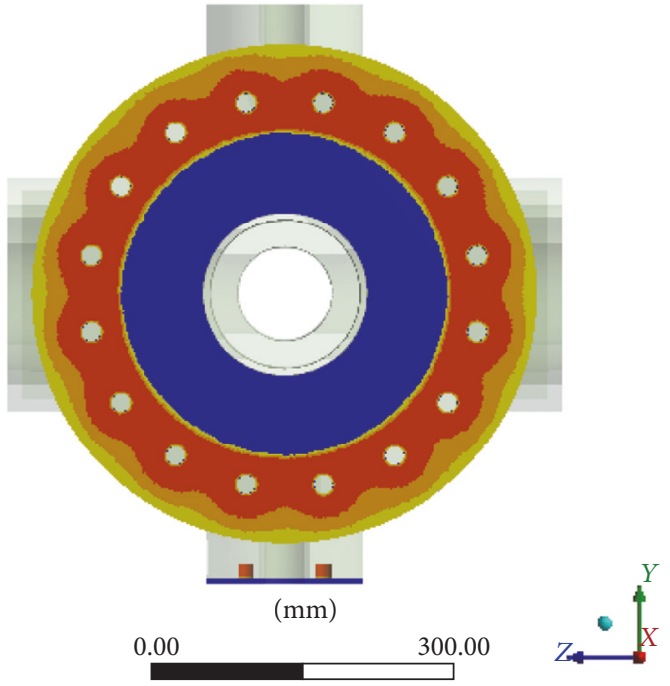

Status

Type: status

Time: 1

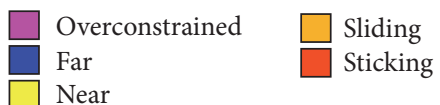

(b) The densely distributed bolted joints

FIGURE 19: Different contact statuses of different distribution densities of the bolted joints. The purple key represents that the contact surfaces are overconstrained and some contact constraints need to be removed. The yellow key indicates that there is a very small gap between the contact surfaces.

the small fraction of skid under them were concentrated in approximate annular regions around screw holes, as shown in Figure 19(a). The area ratio of the bonded region and the whole contact region on these bolted interfaces was less than $50 \%$. However, the bonded regions around the screw holes on the interfaces between other parts, such as the interfaces between cylinders and connection drums, overlapped with each other, as shown in Figure 19(b). The area ratio of the bonded region and the whole contact region on these bolt connected interfaces was more than $80 \%$. It was indicated that the interfaces between bolted flanges were not completely bonded, and the surface-bonded method will overestimate the MNFs because the whole interface between bolted flanges was assumed to be bonded in this method. The difference on contact statuses was mainly caused by the difference on the distribution density of the bolted joints. The area of the bonded region increased as the number of bolted joints between bolted flanges increased. 

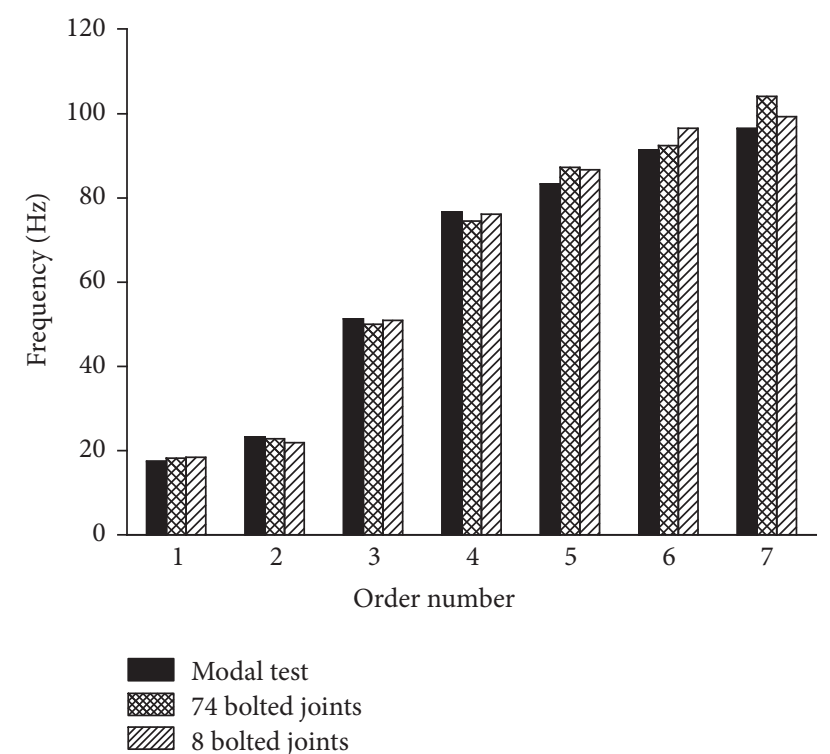

Figure 20: Comparison of MNFs between solid element models with different number of bolted joints and experimental results.

4.2.3. The Key Bolted Joints of the Compressor. To study the influence of the distribution of bolted joints on the low-order vibration modes of the compressor and identify key bolted joints among these 74 bolted joints, we removed the bolted joints between interfaces whose contact status was similar to that shown in Figure 19(b) and set the type of surfaceto-surface contact pairs between these interfaces as bonded instead of frictional. This means the pretension forces and contact behaviours of only 8 bolted joints connected with two cylinder supports (groups of (1), (2), (9), and (10) in Figure 1) were included in this model. The comparison of the low-order MNFs between the solid element model with different numbers of bolted joints and experimental results is shown in Figure 20. It can be seen that the deviation of the low-order MNFs between the solid element model including 8 bolted joints and the modal test ranged from $-5.2 \%$ to $5.7 \%$. Compared with the solid element model including 74 bolted joints, the model including 8 bolted joints kept good simulation accuracy but saved $54.4 \%$ of computation time (as shown in Table 1). Consequently, these 8 bolted joints sparsely distributed on cylinder supports were key bolted joints of the compressor.

Using the above analyses, we can see that the characteristics of bolted joints will affect the low-order vibration modes of the compressor. The sparsely distributed bolted joints with a small bonded region on the contact surface were key bolted joints which had significant impacts on the low-order vibration modes of the compressor. Nevertheless, the characteristics of the densely distributed bolted joints can be ignored to improve the calculation efficiency. During numerical modelling for the assembly containing multiple bolted joints such as the compressor, the outer diameters of theoretical bonded regions on the interfaces between bolted flanges can be predicted using (2). Then, areas of the theoretical bonded region and the entire contact surface can be calculated. Thus, the area ratio between them can be
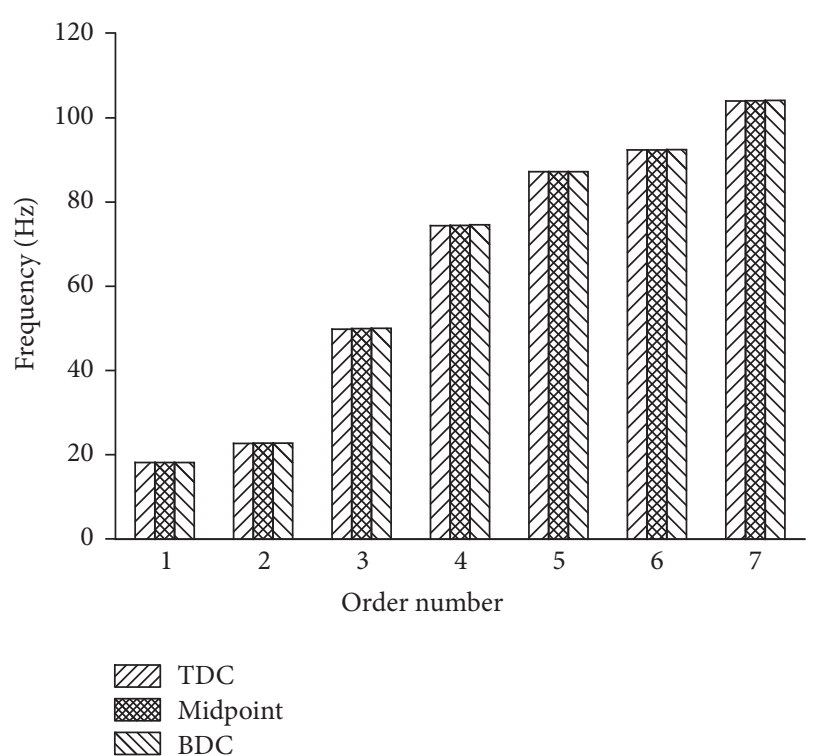

FIgURE 21: Comparison of MNFs between different positions of moving parts.

estimated. The bolted joints between flanges with an area ratio of less than $80 \%$, especially less than $50 \%$, might be key bolted joints of the assembly, and their characteristics should be considered in the numerical model. However, the bolted joints between flanges with an area ratio of more than $80 \%$ can be ignored, and the bolted interfaces between them can be simplified as bonded contacts. Thus, computation time can be saved under the premise of ensuring the calculation accuracy.

4.3. Effects of Positions of Moving Parts on Vibration Modes of the Compressor. Figure 21 shows a comparison of the loworder MNFs between three cases with different positions of moving parts in the solid element model with the boltpretension method. It can be seen that the MNFs slightly increased in order of TDC, midpoint, and BDC, because the overall stiffness of the compressor decreased with the increase of distance between reciprocating moving parts and the crankcase. However, the deviations of the first seven MNFs among these three cases were less than $1.0 \%$. There are two main reasons for this. First, the total reciprocating mass of this compressor is $148.1 \mathrm{~kg}$, which is only $1.2 \%$ of the total weight of the compressor. Second, the distance between TDC and BDC is $0.1 \mathrm{~m}$, which is only $2.0 \%$ of the total length of the compressor along the axis of the cylinder. It was indicated that the positions of moving parts had little impact on vibration modes of the compressor.

\section{Conclusions}

The effects of element types, bolted joints, and positions of moving parts on the low-order vibration modes of a reciprocating compressor were studied by numerical simulation and experimental validation. The following conclusions can be drawn from this study: 
(1) The shell element model was recommended for predicting the low-order vibration modes of assemblies such as the reciprocating compressor with regard to effectiveness and usefulness.

(2) The sparsely distributed bolted joints with small bonded regions on the contact surface were the key bolted joints which had greater impacts on the loworder vibration modes of the assembly than the densely distributed bolted joints.

(3) The positions of moving parts had little effect on loworder vibration modes of the reciprocating compressor.

\section{Conflicts of Interest}

The authors declare that there are no conflicts of interest regarding the publication of this paper.

\section{Acknowledgments}

This work was supported by CNOOC (China National Offshore Oil Corporation) under Contract Z5TZENT089.

\section{References}

[1] X. Q. Dang and S. W. Chen, Gas Pulsation and Vibration in Reciprocating Compressor Piping System, Xian Jiaotong University Press, Xian, China, 1984.

[2] A. W. Benjamin, "Mechanical modeling of compressor manifold systems," http://www.docin.com/p-608370324.html, 2006.

[3] C. Harper, P. Eng, and H. Wu, "Optimized skid design for compressor packages," http://www.betamachinery.com/assets/ pdfs/Technical_Articles/Optimized_Skid_Design_for_Compressor_Packages.pdf, 2013.

[4] M. Passeri, R. Bagagli, and C. Maggi, "Compressor General Arrangement Dynamic Design Guided by Preliminary Cylinder Manifold Forced Response," in Proceedings of the ASME 2015 Pressure Vessels and Piping Conference, 10 pages, Boston, Mass, USA, 2015.

[5] J. D. Pratt and G. Pardoen, "Numerical modeling of bolted lap joint behavior," Journal of Aerospace Engineering, vol. 15, no. 1, pp. 20-31, 2002.

[6] H. Ahmadian and H. Jalali, "Identification of bolted lap joints parameters in assembled structures," Mechanical Systems and Signal Processing, vol. 21, no. 2, pp. 1041-1050, 2007.

[7] J. Kim, J.-C. Yoon, and B.-S. Kang, "Finite element analysis and modeling of structure with bolted joints," Applied Mathematical Modelling, vol. 31, no. 5, pp. 895-911, 2007.

[8] E. Guzas, K. Behan, and J. Davis, “3D finite element modeling of single bolt connections under static and dynamic tension loading," Shock and Vibration, vol. 2015, Article ID 205018, 12 pages, 2015.

[9] J. G. Williams, R. E. Anley, D. H. Nash, and T. G. F. Gray, "Analysis of externally loaded bolted joints: Analytical, computational and experimental study," International Journal of Pressure Vessels and Piping, vol. 86, no. 7, pp. 420-427, 2009.

[10] A. Abidelah, A. Bouchaïr, and D. E. Kerdal, "Influence of the flexural rigidity of the bolt on the behavior of the T-stub steel connection," Engineering Structures, vol. 81, pp. 181-194, 2014.
[11] L. Gaul and J. Becker, "Damping prediction of structures with bolted joints," Shock and Vibration, vol. 17, pp. 359-371, 2010.

[12] K. E. Behan, E. L. Guzas, J. R. Milburn, and S. M. Moss, "Finite element modeling of K-Monel bolts under static loading and dynamic shock loading," Shock and Vibration, vol. 20, no. 3, pp. 575-589, 2013.

[13] C. Hammami, E. Balmes, and M. Guskov, "Numerical design and test on an assembled structure of a bolted joint with viscoelastic damping," Mechanical Systems and Signal Processing, vol. 70-71, pp. 714-724, 2016.

[14] S. Qin, J. Kang, and Q. Wang, "Operational Modal Analysis Based on Subspace Algorithm with an Improved Stabilization Diagram Method," Shock and Vibration, vol. 2016, Article ID 7598965, 10 pages, 2016.

[15] F. Aras, L. Krstevska, G. Altay, and L. Tashkov, "Experimental and numerical modal analyses of a historical masonry palace," Construction and Building Materials, vol. 25, no. 1, pp. 81-91, 2011.

[16] D. Ribeiro, R. Calçada, R. Delgado, M. Brehm, and V. Zabel, "Finite element model updating of a bowstring-arch railway bridge based on experimental modal parameters," Engineering Structures, vol. 40, pp. 413-435, 2012.

[17] E. Denimal, L. Nechak, J.-J. Sinou, and S. Nacivet, "Kriging Surrogate Models for Predicting the Complex Eigenvalues of Mechanical Systems Subjected to Friction-Induced Vibration," Shock and Vibration, vol. 2016, 22 pages, 2016.

[18] R. S. Minette, S. F. SilvaNeto, L. A. Vaz, and U. A. Monteiro, "Experimental modal analysis of electrical submersible pumps," Ocean Engineering, vol. 124, pp. 168-179, 2016.

[19] M. A. Shah, F. Iqbal, I. A. Shah, and B. Lee, "Modal Analysis of a Single-Structure Multiaxis MEMS Gyroscope," Journal of Sensors, vol. 2016, 8 pages, 2016.

[20] Y. Ni, X. Lu, and W. Lu, "Operational modal analysis of a high-rise multi-function building with dampers by a Bayesian approach," Mechanical Systems and Signal Processing, vol. 86, pp. 286-307, 2017.

[21] Gas Machinery Research Council, GMRC Guideline for HighSpeed Reciprocating Compressor Packages for Natural Gas Transmission and Storage Applications, ACI Services Inc, Ohio, USA, 2013.

[22] D. X. Chen, Mechanical Design Handbook, Chemistry Industry Publisher, Beijing, China, 2004.

[23] X. M. Wang, Y. Q. Li, and H. W. Xu, ANSYS Structural Analysis Element and Application, China Communication Press, Beijing, China, 2011. 


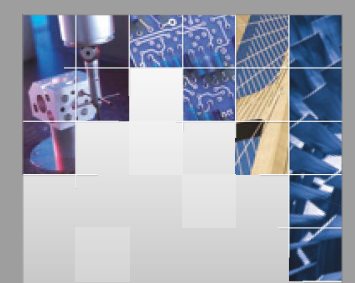

\section{Enfincering}
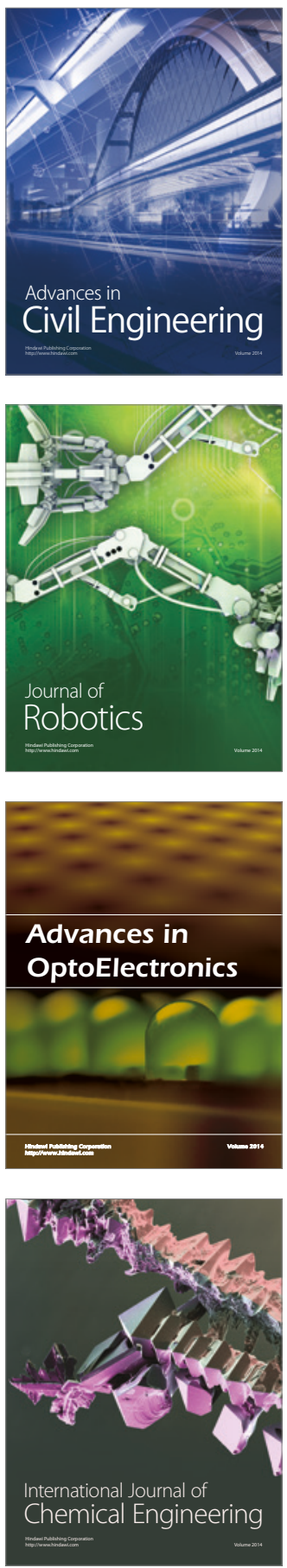

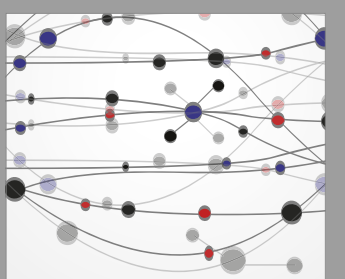

The Scientific World Journal

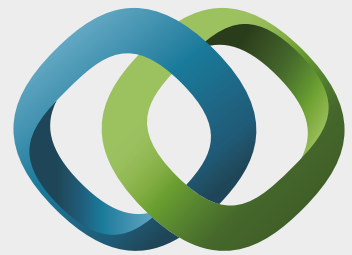

\section{Hindawi}

Submit your manuscripts at

https://www.hindawi.com
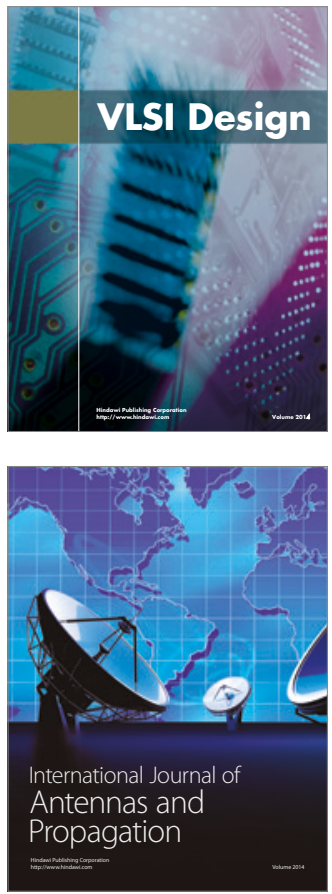

\section{Rotating}

Machinery
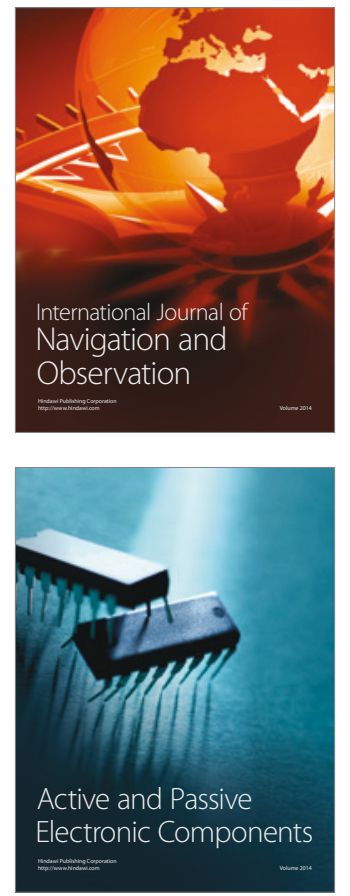
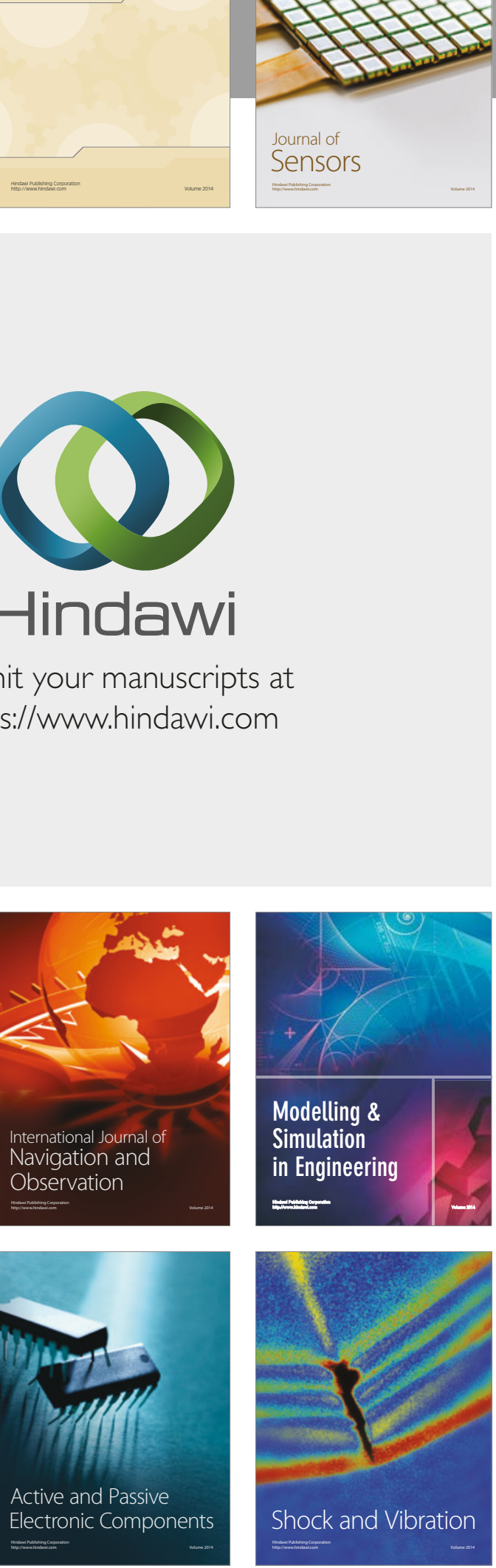
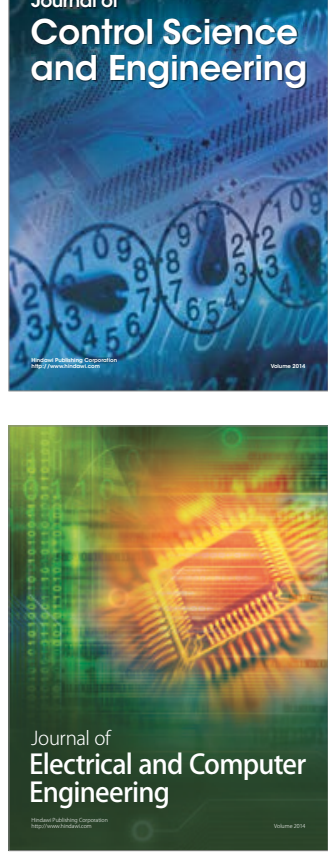

Distributed

Journal of

Control Science

and Engineering
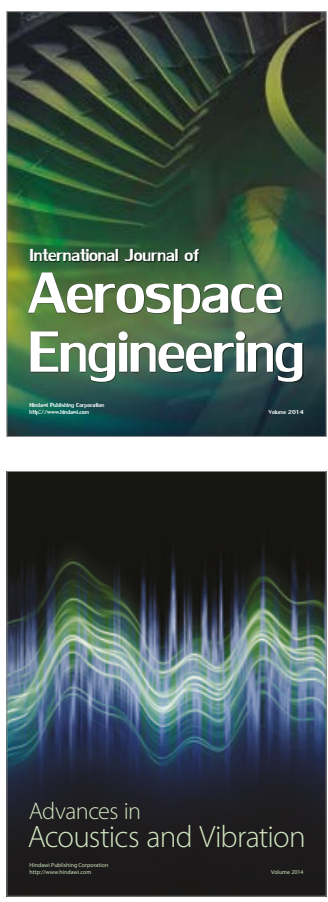

Sensor Networks 